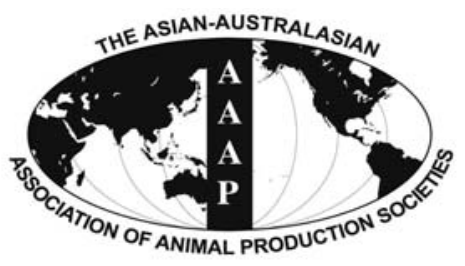

Asian-Aust. J. Anim. Sci.

Vol. 23, No. 1 : 98 - 105

January 2010

www.ajas.info

\title{
Effects of Oxidative Stress Induced by Diquat on Arginine Metabolism of Postweaning Pigs*
}

\author{
Ping Zheng, Bing Yu, Mei Lv and Daiwen Chen** \\ Institute of Animal Nutrition, Sichuan Agricultural University, Key Laboratory of Animal Disease-resistant Nutrition, \\ Ministry of Education, Ya'an, Sichuan, 625014, China
}

\begin{abstract}
A total of 16 crossbred post-weaning pigs $(10.64 \pm 0.27 \mathrm{~kg} \mathrm{BW})$ were individually penned and assigned to one of two treatments to investigate the influences of diquat-induced oxidative stress on performance and arginine metabolism. Pigs in the oxidative stress group were injected intra-peritoneally with $10 \mathrm{mg} / \mathrm{kg} \mathrm{BW}$ of diquat, while the control group were injected with isotonic saline. All pigs were fed ad libitum. The experiment lasted for 7 days. The results indicated that compared with control treatment, oxidative stress induced by diquat significantly decreased average daily gain, intake and feed conversion. The treatment decreased activities of antioxidant enzymes, increased concentration of malondialdehyde in plasma, increased cationic amino acid transporter-1 mRNA level and activity of ornithine aminotransferase and concentrations of arginine and citrulline in the jejunum, decreased the concentrations of arginine in plasma and kidney, and decreased induced nitric oxide synthase mRNA level. It is concluded that oxidative stress induced by diquat can influence absorption and metabolism of arginine and consequently modify the requirement of arginine for post-weaning pigs. (Key Words : Pigs, Diquat, Oxidative Stress, Arginine Metabolism)
\end{abstract}

\section{INTRODUCTION}

Reactive oxygen species (ROS) include superoxide anion, hydrogen peroxide and derivative hydroxyl radical and hydroxide, and lipid peroxides and derivatives peroxyl radicals (Nappi and Vass, 1998). Under normal circumstances, abundant antioxidant enzymes (e.g., superoxide dismutases and glutathione peroxidases) metabolize these highly reactive derivatives of normal oxidative metabolism. If ROS were not removed in a timely manner by an antioxidant system, an imbalance between free radical generation and removal would lead to oxidative stress. Mammalian cells may encounter oxidative stresses that cause destruction of macromolecules and abnormal function (Jang et al., 2008). The flux of ROS increasing in the vasculature will lead to the initiation and promotion of various human pathological conditions (Loscalzo, 2004; Yang, 2006).

\footnotetext{
* This study was supported by Program for Changjiang Scholars and Innovative Research Team in University with grant No. IRTO555-5, China Ministry of Education.

** Corresponding Author: Daiwen Chen. Tel: +86-0835-2885106, Fax: +86-0835-2885106, E-mail: daiwenc@yahoo.com

Received May 5, 2009; Accepted July 9, 2009
}

Diquat is a moderately toxic chemical that utilizes molecular oxygen to produce superoxide anion radical and subsequently hydrogen peroxide. Diquat does not bind covalently with biological molecules but stimulates cellular production of ROS by undergoing cyclic reductionoxidation processes (Spalding et al., 1989). The oral half lethal dose (LD50) for diquat in rats is $120 \mathrm{mg} / \mathrm{kg}$. Studies on wild-type mice found that intraperitoneal injection, at one-tenth of LD50, could induce oxidation stress and couldn't kill the animal (Fu et al., 1999). Liang et al. (2007) used the model of diquat $(50 \mathrm{mg} / \mathrm{kg} \mathrm{BW})$ to study the effect of glutathione peroxidase 4 on against oxidative stress in mice. Our group has established a model for oxidative stress of weaned pigs via administration of diquat at the dose of $12 \mathrm{mg} / \mathrm{kg}$ BW. The activities of antioxidant enzymes were decreased for all the diquat-treated pigs (Yuan et al., 2007).

Arginine is a basic amino acid and serves as an essential precursor for the synthesis of biologically important molecules such as protein, ornithine, proline, polyamines, creatinine, nitric oxide and agmatine (Wu and Morris, 1998). Although most mammals synthesize arginine (except for cats and ferrets), it is a nutritionally essential amino acid for young mammals and adults during times of stress and illness (Wu et al., 1997). Many researchers have studied 
arginine transport and metabolism in a wide variety of catabolic states, including sepsis, burn injury, acidosis, and cancer and these studies have shown that arginine transport activity was increased (Pacitti et al., 1992; Inoue and Souba, 1993; Inoue et al., 1994; Rafferty et al., 1994; Pan et al., 2001; Pan et al., 2004). Arginine levels in plasma were markedly reduced in patients with sepsis and pig model of sepsis (Luiking et al., 2004). Thus regulation of arginine homoeostasis, which depends on dietary arginine intake, whole-body protein turnover, arginine synthesis and catabolism, is of considerable nutritional and physiological significance.

It is now know that arginine plays important roles in many diverse processes, including vasodilation, diseases and stresses. However, little is known about the alterations of arginine metabolism during oxidative stress in pigs. A better knowledge of these alterations may help in proposing a new nutritional strategy to alleviate such stress. In the present study, we will evaluate the effect of diquat-induced oxidative stress on arginine metabolism in piglets through examining the transporter, enzymes and metabolites of anabolism and catabolism of arginine.

\section{MATERIALS AND METHODS}

\section{Chemicals}

HPLC-grade methanol was obtained from Fisher Scientific (Pittsburgh, PA). Diquat (dibromide monohydrate, West Chester, PA), D-mannitol, HEPES, dithiothreitol, EDTA, phenylmethyl-sulfonyl fluoride, aprotinin, chymostatin, pepstatin A, Triton X-100, L-ornithine, pyridoxal phosphate, $\alpha$-ketoglutarate, $o$-aminobenzaldehyde, o-phthaldialdehyde, L-arginine, L-citrulline (Sigma, Buchs, Italy) were procured from Sigma (St. Louis, USA). All other chemicals and solvents were of analytical/reagent grade or higher.

\section{Experimental animals and diets}

The experimental protocols used in this study were approved by the Sichuan Agricultural University Institutional Animal Care and Use Committee. Sixteen LY (Landrace $\times$ Yorkshire) weaning piglets of $28 \pm 1 \mathrm{~d}$ of age were chosen to perform the trail. After 7-day adaptation, the pigs $(35 \pm 1 \mathrm{~d})$ weighed $10.64 \pm 0.27 \mathrm{~kg} \quad \mathrm{BW}$ were individually penned and allocated to two treatments on the basis of body weight $(n=8)$.

The diets were prepared based on corn-soybean meal. Nutrient levels met the requirements of $10-20 \mathrm{~kg}$ pigs according to NRC (1998) (Table 1). The feed were offered five meals at 0800, 1100, 1400, 1700, 2000 and waters available from nipple drinkers. Piglets were housed individually in each cage with a floor $(1 \times 0.8 \mathrm{~m})$ in constant
Table 1. Composition and nutrient levels of experimental diet

\begin{tabular}{lr}
\hline Ingredients & $\%$ \\
\hline Corn & 68.33 \\
Soybean meal & 4.50 \\
Fish meal & 5.50 \\
Whey powder & 6.00 \\
Extruded full-fat soybean meal & 6.50 \\
Zein power & 6.20 \\
L-lysine HCl (78\%) & 0.47 \\
L-threonine & 0.08 \\
Calcium carbonate & 0.90 \\
Calcium phosphate & 1.00 \\
Vitamin mix & \\
NaCl & 0.03 \\
Choline chloride $(50 \%)$ & 0.30 \\
Microelement mix & \\
Neomycin sulfate & 0.10 \\
Sum & 0.08
\end{tabular}

Nutrition levels

Digestible energy (calculated, $\mathrm{MJ} / \mathrm{kg}$ )

Crude protein (analyzed) $\quad 18.56$

Calcium (calculated) $\quad 0.88$

Phosphorus available (calculated) $\quad 0.49$

Lysine (calculated) ${ }^{3} \quad 1.21$

Methionine (calculated) ${ }^{3} \quad 0.38$

Methionine+cystine (calculated) $\quad 0.69$

Tryptophan (calculated) $\quad 0.18$

$\begin{array}{ll}\text { Threonine (calculated })^{3} & 0.77\end{array}$

Arginine (calculated) ${ }^{3} \quad 0.92$

${ }^{1}$ Provided the following per kg of diet: Vitamin A, 15,000 IU; Vitamin $\mathrm{D}_{3}$, 3,000 IU; Vitamin E, $7.5 \mathrm{IU}$; Vitamin $\mathrm{K}_{3}, 1.5 \mathrm{mg}$; Vitamin $\mathrm{B}_{1}, 0.6 \mathrm{mg}$; Vitamin $\mathrm{B}_{2}, 4.8 \mathrm{mg}$; Vitamin $\mathrm{B}_{6}, 1.8 \mathrm{mg}$; Vitamin $\mathrm{B}_{12}, 0.009 \mathrm{mg}$; Nicotinic, $10.5 \mathrm{mg}$; Pantothenic, $7.5 \mathrm{mg}$; Folic acid, $0.15 \mathrm{mg}$; Biotin, 80 mg.

${ }^{2}$ Provided the following per kg of diet: $100 \mathrm{mg} \mathrm{Fe}\left(\mathrm{FeSO}_{4} \cdot 7 \mathrm{H}_{2} \mathrm{O}\right) ; 6 \mathrm{mg}$ $\mathrm{Cu}\left(\mathrm{CuSO}_{4} \cdot 5 \mathrm{H}_{2} \mathrm{O}\right) ; 100 \mathrm{mg} \mathrm{Zn}\left(\mathrm{ZnSO}_{4} \cdot 7 \mathrm{H}_{2} \mathrm{O}\right) ; 4 \mathrm{mg} \mathrm{Mn}\left(\mathrm{MnSO}_{4} \cdot \mathrm{H}_{2} \mathrm{O}\right)$; $0.3 \mathrm{mg} \mathrm{Se}\left(\mathrm{Na}_{2} \mathrm{SeO}_{3} \cdot 5 \mathrm{H}_{2} \mathrm{O}\right) ; 0.14 \mathrm{mg} \mathrm{I}(\mathrm{KI})$.

${ }^{3}$ The levels of lysine, methionine, threonine and arginine were calculated based on amino acids levels in ingredients (including corn, soybean meal, fish meal, whey powder, and extruded full-fat soybean meal and zein power) by analyzed before preparing the diet.

temperature $\left(25-27^{\circ} \mathrm{C}\right)$ animal rooms with a $12 \mathrm{~h}$ light dark cycle.

\section{Experimental design}

According to a single factorial arrangement, all pigs received same diet. Diquat (dibromide monohydrate) was dissolved in isotonic saline and filter-sterilized. The concentration of diquat solution was $10 \mathrm{mg} / \mathrm{ml}$. At the beginning of the experiment, pigs in oxidative stress group received an intraperitoneal injection of diquat at $10 \mathrm{mg} / \mathrm{kg}$ of body weight. Control group was injected the same volume of isotonic saline. All pigs were given free access to 
distilled water and fed ad libitum. The trial lasted for $7 \mathrm{~d}$.

The feed intake of the pigs was record every day and the body weight of the pigs obtained at the beginning and the end of the experiment. Average daily feed intake (ADFI), average daily gain (ADG) and the ratio of gain to feed intake $(\mathrm{G} / \mathrm{F})$ were calculated.

\section{Sample collection}

The blood (10 $\mathrm{ml}$ per pig) was collected from the portal vein precava into heparinized polyethylene tubes (Axygen biotechnology CO., LTD. Taizhou, China) after all the pigs were weighed at the end of the feeding period. Plasma was prepared by centrifuging the blood $(1,200 \times \mathrm{g}, 5 \mathrm{~min})$ and immediately stored at $-20^{\circ} \mathrm{C}$. And all the pigs were fooddeprived for $12 \mathrm{~h}$ and were anesthetized with intravenous injection of phenobarbital $(0.25 \mathrm{mg} / \mathrm{kg}$ bodyweight $)$ and slaughtered by exsanguinations according to protocols approved by the Sichuan Agricultural University Animal Care and Use Committee. A midline laparotomy was performed. The abdomen was incised.

The jejunum (Identified by gut morphology from the junction with duodenum to the junction with ileum) was dissected free of mesentery on a chilled stainless steel tray. The same part of jejunum, kidney, liver, lung samples were removed and snap frozen in liquid nitrogen and then stored at $-80^{\circ} \mathrm{C}$ for assays.

\section{Analytical methods}

Measurement of enzyme activity in plasma: Activities of superoxide dismutases (SOD) and glutathione peroxidases (GPX), capability of inhibiting hydroxyl radical and concentration of malondialdehyde (MDA) in plasma were measured by assay kits from Nanjing Jiancheng Bioengineering Institute. The methods were according to the manufacturer's instructions.

Measurement of amino acids: Plasma amino acids analyzed by L-8800 amino acid analyzer (Hitachi, Japan). Free amino acids were extracted with $10 \%$ sulfosalicylic acid solution.

Arginine and citrulline in jejunum and kidney were analyzed by HPLC methods involving precolumn derivatization with $o$-phthaldialdehyde (OPA) (Wu et al., 2008). The Waters HPLC apparatus consisted of the following: 515 HPLC pump, a Model of 717 plus autosampler, a Model 474 fluorescence detector, and 486 Tunable absorbance detector (Waters Inc., Milford, MA). An external standard of method was adapted for quantitative. Briefly, a frozen tissue sample $(\sim 100 \mathrm{mg})$ was homogenized, with use of a glass homogenizer, in $1 \mathrm{ml}$ of $1.5 \mathrm{M} \mathrm{HClO}_{4}$. The homogenizer was rinsed twice with $\mathrm{H}_{2} \mathrm{O}$ ( $3 \mathrm{ml}$ each). The combined solution was transferred to a 15 $\mathrm{ml}$ polypropylene tube, followed by slow addition of $0.5 \mathrm{ml}$ of $2 \mathrm{M} \mathrm{K}_{2} \mathrm{CO}_{3}$. The tubes were vortexed and centrifuged $(3,000 \times g$ for $5 \mathrm{~min})$ to obtain the supernatant fluid for analysis. Amino acid standard solutions were prepared fresh from arginine and citrulline powders which concentrations were $10 \mu \mathrm{mol} / \mathrm{L}$ and $20 \mu \mathrm{mol} / \mathrm{L}$ and $50 \mu \mathrm{mol} / \mathrm{L}$. To a $4 \mathrm{ml}$ glass tube, add $0.1 \mathrm{ml}$ of $1.2 \%$ benzoic acid, $0.1 \mathrm{ml}$ of an amino acid standard or sample solution, and $1.4 \mathrm{ml} \mathrm{H}_{2} \mathrm{O}$. All tubes were vortexed. The derivatized solution included $25 \mu \mathrm{l}$ standard or sample solution and $25 \mu$ OPA reagent solution was immediately delivered into the HPLC column without any delay time. Mobile phase A was $0.1 \mathrm{~mol} / \mathrm{L}$ sodium acetate ( $\mathrm{pH}$ 7.2). Mobile phase B was $100 \%$ Methanol. A gradient program with a total running time of $35 \mathrm{~min}$ (including the time for column regeneration) at a flow rate of $1.1 \mathrm{ml} / \mathrm{min}$ can be used for the separation of citrulline and arginine. The proportion of mobile phase $\mathrm{B}$ is as follows: $0 \mathrm{~min}, 14 \%$; $15 \mathrm{~min}, 14 \%$; $20 \mathrm{~min}, 30 \%$; $24 \mathrm{~min}$, $35 \%$; $24.1 \mathrm{~min}, 100 \%$; $26 \mathrm{~min}, 100 \%$; $26.1 \mathrm{~min}, 14 \%$; 35 min, 14\%. Fluorescence is monitored at excitation and emission wavelengths of 340 and $450 \mathrm{~nm}$, respectively.

Measurement of OAT activity: The activity of ornithine aminotransferase (OAT) was determined as described by Wu et al. (1997, 1998, and 2005). Briefly, jejunums (0.5 g) were homogenized at $4^{\circ} \mathrm{C}$ in $6 \mathrm{ml}$ of homogenization buffer ((300 mmol/L D-mannitol, $5 \mathrm{mmol} / \mathrm{L}$ HEPES, $0.2 \mathrm{mmol} / \mathrm{L}$ EDTA and $3 \mathrm{mmol} / \mathrm{L}$ dithiothreitol, $\mathrm{pH}$ 7.4, protease inhibitors $(5 \mathrm{mg} / \mathrm{L}$ phenylmethyl-sulfonyl fluoride, $5 \mathrm{mg} / \mathrm{L}$ aprotinin, $5 \mathrm{mg} / \mathrm{L}$ chymostatin and $5 \mathrm{mg} / \mathrm{L}$ pepstatin A)). Homogenates were centrifuged at $600 \times g$ and $4{ }^{\circ} \mathrm{C}$ for 10 min, and the supernatant fraction was centrifuged at $12,000 \times \mathrm{g}$ and $4^{\circ} \mathrm{C}$ for $15 \mathrm{~min}$. The pellet (mitochondria) was resuspended in $1.5 \mathrm{ml}$ of fractionation buffer (300 mmol/L D-mannitol, $5 \mathrm{mmol} / \mathrm{L}$ HEPES, $5 \mathrm{mmol} / \mathrm{L}$ EDTA and $3 \mathrm{mmol} / \mathrm{L}$ dithiothreitol), and centrifuged at $600 \times \mathrm{g}$ and $4^{\circ} \mathrm{C}$ for $4 \mathrm{~min}$. The supernatant fraction was centrifuged at $4,000 \times g$ and $4^{\circ} \mathrm{C}$ for $10 \mathrm{~min}$. The mitochondria (pellets) were suspended in $0.5 \mathrm{ml}$ of the homogenization buffer containing $0.5 \%$ Triton X-100 and used for OAT assay at $37^{\circ} \mathrm{C}$ for 0 or $15 \mathrm{~min}$. The assay mixture $(2 \mathrm{ml})$ consisted of $75 \mathrm{mmol} / \mathrm{L}$ potassium phosphate buffer $(\mathrm{pH} 7.5), 20$ $\mathrm{mmol} / \mathrm{L}$ ornithine, $0.45 \mathrm{mmol} / \mathrm{L}$ pyridoxal phosphate, 5 $\mathrm{mmol} / \mathrm{L} \quad o$-aminobenzaldehyde, 0 or $3.75 \mathrm{mmol} / \mathrm{L} \alpha$ ketoglutarate and mitochondria. At the end of 0 and $15 \mathrm{~min}$ incubation periods at $37^{\circ} \mathrm{C}$, the colorimetric complex resulting from the reaction of pyrroline-5-carboxylate (P5C) and with $o$-aminobenzaldehyde was determined at $440 \mathrm{~nm}$. The colorimetric complex analyzed by UV-1100 spectrophotometer (Mapada, China).

RNA isolation and reverse transcription: Total RNA was extracted from jejunum, liver and lung samples using TRIzol reagent (Sigma) according to the manufacturer's instructions. The concentration of RNA in the final 
Table 2. Gene-specific primers

\begin{tabular}{llcc}
\hline Gene & \multicolumn{1}{c}{ Primer sequence } & GenBank accession (NO.) & Product size (bp) \\
\hline CAT-1 & Forward 5'-gagcaagaccaaactctccttc-3' & NM_001012613 & 137 \\
& Reverse 5'- agcctatcagcatccacactg -3' & & 150 \\
eNOS & Forward 5'- acaggctctcacttcttcct -3' & NM_214295 & 129 \\
& Reverse 5'- aaccacttccactcctcatagc -3' & & 132 \\
iNOS & Forward 5'- acaccccaaatacgagtggttc -3' & U59390 \\
& Reverse 5'- cccatgtaccagccattgaag -3' & & DQ845171 \\
\hline
\end{tabular}

CAT-1 = Cationic amino acid transporter-1; eNOS: Endothelium nitric oxide synthase; iNOS: Induced nitric oxide synthase.

preparations was calculated from the OD260. The integrity of RNA was verified by denaturing agarose gel electrophoresis. Reverse transcription using random hexamer primer and TaKaRa reverse transcriptional reagents. The cDNA was used as template for polymerase chain reaction (PCR).

Real-time quantitative PCR: Real-time quantitative PCR was performed in an Option Monitor 3 Real-Time PCR Detection System (Bio-Rad) using the SYBR Green Supermix (TaKaRa, Japan) For each $20 \mu \mathrm{l} \mathrm{SYBR}$ Green PCR reaction: $2.0 \mu \mathrm{l}$ cDNA, $0.8 \mu$ l sense primer $(100 \mu \mathrm{M})$, $0.8 \mu \mathrm{l}$ anti-sense primer $(100 \mu \mathrm{M}), 10 \mu \mathrm{l} \mathrm{SYBR}$ Green PCR Supermix (TaKaRa, Japan) and $6.4 \mu \mathrm{l}$ PCR-grade water were mixed together. Each sample was amplified in triplicate. The PCR cycling conditions used were: 40 cycles of $95^{\circ} \mathrm{C}$ for $10 \mathrm{~s}, 57.2^{\circ} \mathrm{C}$ for $20 \mathrm{~s}$ for cationic amino acid transporter-1 (CAT-1) or $61^{\circ} \mathrm{C}$ for $20 \mathrm{~s}$ for endothelium nitric oxide synthase (eNOS) and induced nitric oxide synthase (iNOS). The gene-specific primers used are listed in Table 2. All primers were purchased from TaKaRa (Japan). Fluorescence detection was carried out immediately at the end of each annealing step and the purity of the amplification was confirmed by analyzing the melting curves. Relative gene expression to the housekeeping gene $\beta$-actin was performed in order to correct for the variance in amounts of RNA input in the reactions.

Each primer pair used yielded a single peak in the melting curve and a single band with the expected size in agarose gel. The relative gene expressions compared to the housekeeping gene $\beta$-actin were calculated using the Pfaffl and Hageleit (2001) method.

\section{Statistical analysis}

Statistical analysis was carried out using SPSS for analysis of one-way ANOVA. Values in the text are means \pm SEM

\section{RESULTS}

\section{Performance}

The effect of diquat-induced oxidative stress on performance of postweaned pigs was shown in Table 3. Throughout the experimental period, ADFI, ADG and G/F of the stress pigs were decreased by $53.7 \%(\mathrm{p}<0.01), 32.6 \%$ $(\mathrm{p}<0.01)$ and $42.2 \%(\mathrm{p}<0.05)$ respectively compared with the control pigs.

\section{The parameters of oxidative stress in plasma}

The activities of antioxidant enzymes and concentration of MDA in plasma were influenced by oxidative stress (Table 4). The activities of SOD and GPX in the plasma of stress pigs were decreased by $24.9 \%(p<0.01)$ and $36.5 \%$ respectively $(\mathrm{p}<0.05)$ compared with control pigs. The capability of inhibiting hydroxyl radical of stress pigs was lower than control pigs $(\mathrm{p}<0.05)$. Pigs received diquat had significantly higher concentration of MDA than those received isotonic saline in the plasma $(p<0.01)$.

Table 3. Effect of oxidative stress on performance of postweaning pigs

\begin{tabular}{lccc}
\hline & Oxidative stress & Control & $\mathrm{p}$ \\
\hline Initial BW $(\mathrm{kg})$ & $10.74 \pm 0.51$ & $10.56 \pm 0.31$ & 0.758 \\
Final BW (kg) & $11.60 \pm 0.75$ & $12.41 \pm 0.36$ & 0.306 \\
ADG (g/head/d) & $122.4 \pm 39.5$ & $264.4 \pm 16.4$ & 0.003 \\
ADFI (g/head/d) & $277.0 \pm 42.4$ & $410.8 \pm 14.4$ & 0.006 \\
G/F & $0.37 \pm 0.17$ & $0.64 \pm 0.03$ & 0.049 \\
\hline
\end{tabular}

ADFI = Average daily feed intake; $\mathrm{ADG}=$ Average daily gain; $\mathrm{G} / \mathrm{F}=$ The ratio of gain to feed intake.

Oxidative stress: pigs challenged with diquat $(10 \mathrm{mg} / \mathrm{kg} \mathrm{BW})$ and given ad libitum access to feed; Control: pigs given ad libitum access to feed and injected with sterile saline. 
Table 4. Effect of oxidative stress on activities of antioxidant enzymes and MDA in plasma of postweaning pigs

\begin{tabular}{lccc}
\hline & Oxidative stress & Control & $\mathrm{p}$ \\
\hline SOD $(\mathrm{U} / \mathrm{ml})$ & $56.14 \pm 1.58$ & $74.80 \pm 1.50$ & 0.000 \\
CIHR $(\mathrm{U} / \mathrm{ml})$ & $343.97 \pm 48.67$ & $493.61 \pm 30.95$ & 0.020 \\
GPX $(\mathrm{U} / \mathrm{ml})$ & $313.56 \pm 59.53$ & $493.62 \pm 30.95$ & 0.024 \\
MDA $(\mathrm{nmol} / \mathrm{ml})$ & $3.32 \pm 0.11$ & $2.76 \pm 0.07$ & 0.006 \\
\hline
\end{tabular}

SOD = Superoxide dismutase; CIHR = Capability of inhibiting hydroxyl radical; GPX = Glutathione peroxidases; MDA = Levels of malondialdehyde. Oxidative stress: pigs challenged with diquat (10 mg/kg BW) and given ad libitum access to feed; Control: pigs given ad libitum access to feed and injected with sterile saline.

\section{Transporter of arginine CAT-1 mRNA expression in jejunum}

To investigate the influence of oxidative stress induced by diquat on arginine transport in pigs, we quantified the mRNA levels of CAT-1 in jejunum. As shown in Figure 1, the CAT-1 mRNA level in stress group was increased by $87 \%(\mathrm{p}<0.01)$ compared to control group.

\section{The activity of endogenous synthetase of arginine in jejunum}

The activity of OAT in jejunum was influenced by oxidative stress. Pigs received diquat had significantly higher activity of OAT than control group $(2.75 \pm 0.05 \mathrm{mmol}$ $\mathrm{P} 5 \mathrm{C} / \mathrm{min} \cdot \mathrm{g}$ tissue vs. $2.60 \pm 0.05 \mathrm{mmol} \mathrm{P} 5 \mathrm{C} / \mathrm{min} \cdot \mathrm{g}$ tissue, $\mathrm{p}<0.01)$.

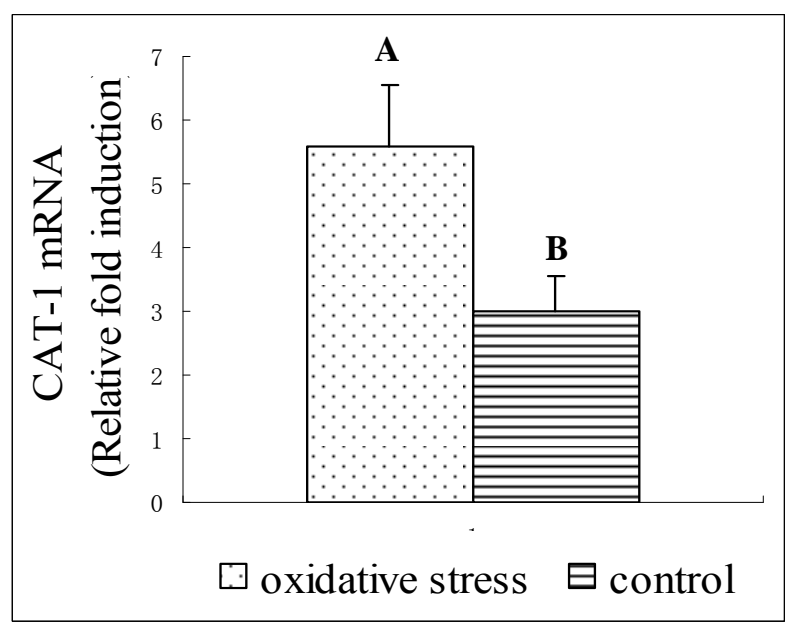

Figure 1. The influence of oxidative stress induced by diquat on CAT-1 mRNA expression in jejunum. A, B Treatments with different letters are different at $\mathrm{p}<0.01$.

\section{Amino acid concentrations in plasma}

Concentrations of arginine, citrulline and ornithine in plasma were influenced by oxidative stress (Table 5). The concentration of ornithine in stress group was increased by $48.2 \%(p<0.01)$ compared to control group. Oxidative stress group had significantly lower concentration of arginine than control group in the plasma $(\mathrm{p}<0.05)$. But the concentration of citrulline did not differ between the groups.

\section{Amino acid concentrations in jejunum and kidney}

Concentrations of arginine and citrulline in jejunum and kidney were influenced by oxidative stress (Table 6). The concentrations of citrulline and arginine in jejunum of stress group had significantly higher than control group $(\mathrm{p}<0.01)$. However, the concentrations of citrulline and arginine in kidney of stress group were lower than control group $(\mathrm{p}<0.05)$.

\section{Expressions of iNOS and eNOS mRNA in liver and lung}

To investigate the effects of oxidative stress on arginine catabolism, we quantified the mRNA levels of iNOS and eNOS in liver and lung. As shown in Table 7, the eNOS mRNA level in the liver of the oxidative stress group tended to be lower than control group. The iNOS mRNA level in the liver of the oxidative stress group was significantly lower than control group $(\mathrm{p}<0.01)$. The eNOS mRNA level in the lung of the oxidative stress group tended to be lower than control group $(p=0.073)$. The iNOS mRNA level in the lung of the oxidative stress group was lower than control group $(\mathrm{p}<0.05)$.

\section{DISCUSSION}

Diquat dibromide is a commercially available herbicide

Table 5. Effect of oxidative stress on amino acid concentrations in plasma of postweaning pigs

\begin{tabular}{lccc}
\hline & Oxidative stress & Control & $\mathrm{p}$ \\
\hline Citrulline $(\mu \mathrm{g} / \mathrm{ml})$ & $25.9 \pm 2.5$ & $22.6 \pm 0.8$ & 0.239 \\
Arginine $(\mu \mathrm{g} / \mathrm{ml})$ & $42.8 \pm 2.1$ & $50.1 \pm 1.9$ & 0.032 \\
Ornithine $(\mu \mathrm{g} / \mathrm{ml})$ & $36.3 \pm 1.7$ & $24.5 \pm 1.7$ & 0.002 \\
\hline
\end{tabular}

Oxidative stress: pigs challenged with diquat (10 mg/kg BW) and given ad libitum access to feed; Control: pigs given ad libitum access to feed and injected with sterile saline. 
Table 6. Effect of oxidative stress on arginine and citrulline concentration of jejunum and kidney in postweaning pigs

\begin{tabular}{lccc}
\hline & Oxidative stress & Control & $\mathrm{p}$ \\
\hline Jejunum & & & 0.000 \\
Citrulline (nmol/g tissue) & $700.19 \pm 7.06$ & $546.85 \pm 20.34$ & 0.003 \\
$\quad$ Arginine (nmol/g tissue) & $771.39 \pm 63.07$ & $441.56 \pm 24.76$ & 0.018 \\
Kidney & & & 0.021 \\
Citrulline (nmol/g tissue) & $440.40 \pm 18.13$ & $511.57 \pm 15.68$ & $770.21 \pm 54.84$ \\
Arginine (nmol/g tissue) & $537.30 \pm 44.85$ & & \\
\hline
\end{tabular}

Oxidative stress: pigs challenged with diquat (10 mg/kg BW) and given ad libitum access to feed; Control: pigs given ad libitum access to feed and injected with sterile saline.

that is used extensively worldwide. In Yuan's study (2007), at the beginning of post-injection, vomiting and anorexia occurred for all the diquat-treated pigs. So, in this study, we used the dose of $10 \mathrm{mg} / \mathrm{kg} \mathrm{BW}$ to induce oxidative stress by intraperitoneal injection on postweaning pigs. GPX and SOD are the main antioxidant enzymes in mammals, and these enzymes could reduce hydrogen peroxide $\left(\mathrm{H}_{2} \mathrm{O}_{2}\right)$ and organic hydro peroxides. Their activities are commonly used to assess body antioxidative status (Knight and Sunde, 1987). The activities of antioxidant enzymes were decreased due to the feed back of $\mathrm{H}_{2} \mathrm{O}_{2}$ or inactivated by the $\mathrm{O}_{2}$, these could be regarded as the protective effect of the bodies when encounter the changes of environmental factors (Peled-Kamar et al., 1997). In this study, the activities of the antioxidative enzymes in the plasma of diquat-treated pigs were significantly decreased and the concentration of MDA in plasma was increased, which indicated that antioxidative capabilities of pigs were damaged in this experiment. The model of oxidative stress of pigs induced by diquat was successful.

In this experiment, the performance of the pigs injected with diquat decreased compared to those of pigs injected with isotonic saline. In our study, diquat-treated pigs reduced gain: feed ratios by $42.2 \%$, compared with those of control pigs. These results were consistent with other study (Yuan et al., 2007). Our experiment indicated oxidative stress induced by diquat decreased growth rates and feed efficiency.

The intestinal epithelium plays a central role in maintaining the arginine homeostasis by providing exogenous arginine into the system. Arginine, transported into the epithelium from the intestinal lumen, is either metabolized inside the epithelium or transported across the basolateral membrane into circulation as metabolites or free arginine. Changes of the intestinal epithelial brush border membrane arginine transport activity reflect the status of both local enterocyte's arginine metabolism as well as whole organ system arginine metabolism (Pan et al., 2004). Animal studies showed that arginine was predominantly transported across the intestinal membrane via a $\mathrm{Na}^{+}$independent CAT-1 (White, 1985; Closs et al., 2004). Our experiment showed that oxidative stress induced by diquat increased CAT-1 mRNA level compared to control group $(p<0.01)$ in jejunum of the postweaning pigs. Similar stimulation of arginine transport was observed in cultured intestinal epithelial Caco-2 cells exposed to lipopolysaccharide and interferon- $\gamma$ (Pan et al., 2001). The results were consistent with the research results of Aulak (1999) and Fernandez (2003). Their researches showed that arginine deprivation resulted in increased expression of CAT-1. Our result indicated that oxidative stress resulted in increased expression of CAT-1, which might reflect an increased arginine requirement in oxidative stress condition.

In postweaning pigs, pyrroline-5-carboxylate is the common intermediate in pathways the synthesis of citrulline from both glutamine and proline; it is interconvert into ornithine by OAT in enterocytes (Wu et al., 1997). An inhibition of OAT will lead to decreased synthesis of citrulline and arginine from both glutamine and proline in enterocytes, thereby resulting in arginine deficiency, as in

Table 7. The influence of oxidative stress induced by diquat on eNOS and iNOS mRNA expression in postweaning pigs

\begin{tabular}{lccc}
\hline & Oxidative stress & Control & $\mathrm{p}$ \\
\hline Liver & & & 0.729 \\
$\quad$ eNOS & $3.81 \pm 0.62$ & $4.17 \pm 0.81$ & 0.04 \\
iNOS & $2.03 \pm 0.20$ & $3.00 \pm 0.03$ & 0.073 \\
Lung & & & 0.014 \\
eNOS & $1.80 \pm 0.12$ & $2.23 \pm 0.19$ & $1.89 \pm 0.07$ \\
iNOS & $1.51 \pm 0.10$ & & \\
\hline
\end{tabular}

Oxidative stress: pigs challenged with diquat $(10 \mathrm{mg} / \mathrm{kg} \mathrm{BW})$ and given ad libitum access to feed; Control: pigs given ad libitum access to feed and injected with sterile saline. 
OAT-gene knockout mice (Wang et al., 1995). We found the activity of OAT in jejunum was significantly increased by diquat-induced oxidative stress. Endogenous synthesis of arginine would be increased to maintain the stability of the whole arginine metabolism under oxidative stress. We also detected the concentration of arginine and citrulline in plasma and jejunum and kidney. At first we found that the concentration of arginine and citrulline in jejunum of oxidative stress group had significantly higher than control group. The results consisted with gene expression of arginine transporter CAT-1 and activity of key enzyme for synthesis arginine in jejunum. And oxidative stress group had significantly higher concentration of ornithine than control group in plasma. Second, oxidative stress group had significantly lower concentration of arginine than control group in plasma and kidney. This result indicated that the requirement of arginine metabolism might be increased in critical condition and plasma arginine availability might become rate limiting when exogenous arginine administration was not enough. So, whether the exogenous arginine administration will be improving the situation of arginine in vivo under oxidative stress need further research.

The expression of iNOS and the increase in the oxidative stress seem to be responsible for the failure of lung and liver (Crespo et al., 1999). In order to estimate the effects of oxidative stress on arginine catabolism of tissue in postweaning pigs, real time RT-PCR technique was used to quantify the mRNA levels of iNOS and eNOS in liver and lung. Our experiment showed that oxidative stress induced by diquat resulted in decreased the level of iNOS mRNA $(p<0.05)$ and trended to decrease the level of eNOS mRNA in liver and lung. Other researchers' studies showed that arginine deprivation results in decreased expression of iNOS. These changes occur via reduced translational efficiency of iNOS messenger RNA (mRNA) (Lee, 2003), decreased stability of iNOS protein (El-Gayar, 2003). Our result indicated that oxidative stress depressed iNOS mRNA could be result by decreasing arginine availability.

In summary, oxidative stress induced by diquat in pigs depressed the growth performance, increased CAT-1 mRNA level and activity of ornithine aminotransferase, increased the concentrations of arginine and citrulline in jejunum decreased the concentrations of arginine in plasma and kidney. The results indicated that oxidative stress would increase the amounts of arginine for metabolism and arginine availability in circulation may become limited, which result in the increase of endogenous arginine synthesis. The underlying mechanism and whether the exogenous arginine administration will be beneficial to pig health under oxidative stress need further research.

\section{ACKNOWLEDGMENTS}

We are grateful to Chuanming Chen for HPLC technical assistance.

\section{REFERENCES}

Aulak, K. S., R. Mishra, L. Zhou, S. L. Hyatt, W. Jonge, W. Lamers, M. Snider and M. Hatzoglou. 1999. Posttranscriptional regulation of the arginine transporter Cat-1 by amino acid availability. J. Biol. Chem. 274:30424-30432.

Closs, E. I., A. Simon, N. Vékony and A. Rotmann. 2004. Plasma membrane transporters for arginine. J. Nutr. 134:2752s-2759s.

Crespo, E., M. Macías, D. Pozo, G. Escames, M. Martín, F. Vives, J. M. Guerrero and D. Acuña-Castroviejo. 1999. Melatonin inhibits expression of the inducible no synthase ii in liver and lung and prevents endotoxemia in lipopolysaccharide-induced multiple organ dysfunction syndrome in rats. FASEB J. 13:1537-1546.

Dillon, E. L., D. A. Knabe and G. Wu. 1999. Lactate inhibits citrulline and arginine synthesis from proline in pig enterocytes. Am. J. Physiol. Gastrointest. Liver Physiol. 276:1079-1086.

El-Gayar, S., H. Thuring-Nahler, J. Pfeilschifter, M. Rollinghoff and C. Bogdan. 2003. Translational control of inducible nitric oxide synthase by IL-13 and arginine availability in inflammatory macrophages. J. Immunol. 171:4561-4568.

Fernandez, J., A. B. Lopez, C. Wang, R. Mishra, L. Zhou, I. Yaman, M. D. Snider and M. Hatzolgou. 2003. Transcriptional control of the arginine/lysine transporter, cat-1, by physiological stress. J. Biol. Chem. 278:50000-50009.

Fu, Y., W. H. Cheng, J. M. Porres, D. A. Ross and X. G. Lei. 1999. Knockout of cellular glutathione peroxidase gene renders mice susceptible to diquat-induced oxidative stress. Free Radic. Biol. Med. 27:605-611.

Jang, H. Y., H. S. Kong, J. D. Oh, B. K. Park, B. K. Yang, G. J. Jeon and H. K. Lee. 2008. Maintenance of sperm characteristics and in vitro developmental rate of embryos against oxidative stress through antioxidants in pig. Asian-Aust. J. Anim. Sci. 21(3):340-345.

Inoue, Y., B. P. Bode and W. W. Souba. 1994. Hepatic $\mathrm{Na}^{+}-$ independent amino acid transport in endotoxemia rats: evidence for selective stimulation of arginine transport. Shock 2:164-170.

Inoue, Y. and W. W. Souba. 1993. Cyclooxygenase blockage abrogates hepatic arginine uptake in endotoxemic rats. Surg. Forum 44:7-10.

Knight, S. A. B. and R. A. Sunde. 1987. The effect of progressive selenium deficiency on anti-glutathione peroxidase antibody reactive protein in rat liver. J. Nutr. 117:732-738.

Liang, H. Y., H. V. Remmen, V. Frohlich, J. Lechleiter, A. Richardson and Q. T. Ran. 2007. Gpx4 protects mitochondrial ATP generation against oxidative damage. Biochem. Biophys. Res. Commun. 356:893-898.

Loscalzo, J. 2004. L-Arginine and atherothrombosis. J. Nutr. 134 (10):2798S-2800S.

Luiking, Y. C., M. M. Hallemeesch, Y. L. Vissers, W. H. Lamers and N. E. Deutz. 2004. In vivo whole body and organ arginine metabolism during endotoxemia (sepsis) is dependent on mouse strain and gender J. Nutr. 134:2768S-2774S.

Nappi, A. J. and E. Vass. 1998. Hydroxyl radical formation via iron-mediated fenton chemistry is inhibited by methylated 
catechols. Biochim. Biophys. Acta. 1425(1):159-167.

Pacitti, A. J., E. M. Copeland and W. W. Souba. 1992. Stimulation of hepatocyte System y $(+)$-mediated L-arginine transport by an inflammatory agent. Surgery 112:403-411.

Pan, M., H. A. Choudry, M. J. Epler, Q. H. Meng, A. Karinch, C. M. Lin and W. Souba. 2004 Arginine transport in catabolic disease states. J. Nutr. 134:2826S-2829S.

Pan, M., A. M. Karinch, C. M. Lin and W. W. Souba. 2001. Interferon- $\gamma$ stimulates arginine transport in intestinal epithelium. Surg. Forum 52:159-162.

Peled-Kamar, M., J. Lotem, I. Wirguin, L. Weiner, A. Hermalin and Y. Groner. 1997. Oxidative stress mediates impairment of muscle function in transgenic mice with elevated level of wildtype $\mathrm{Cu} / \mathrm{Zn}$ superoxide dismutase. Proc. Natl. Acad. Sci. 94:3883-3887.

Pfaffl, M. W. 2001. A new mathematical model for relative quantification in real-time RT-PCR. Nucleic Acids Res. 29:2002-2007.

Rafferty, J. F., Y. Noguchi, J .E. Fischer and P. O. Hasselgren. 1994. Sepsis in rats stimulates cellular proliferation in the mucosa of the small intestine. Gastroenterology 107:121-127.

Spalding, D. J., J. R. Mitchell, H. Jaeschke and C. V. Smith. 1989. Diquat hepatotoxicity in the Fischer-344 rat: the role of covalent binding to tissue proteins and lipids. Toxicol. Appl. Pharmacol. 101(2):319-327.

Wang, T., A. M. Lawler, G. Steel, I. Sipila, A. H. Milam and D. Valle. 1995. Mice lacking ornithine-delta-aminotransferase have paradoxical neonatal hypoornithinaemia and retinal degeneration. Nat. Genet. 11(2):185-190.
White, M. F. 1985. The transport of cationic amino acids across the plasma membrane of mammalian cells. Biochem. Biophys. Acta. 822:355-374.

Wu, G. and S. M. Morris Jr. 1998. Arginine metabolism: nitric oxide and beyond. Biochem. J. 336:1-17.

Wu, G., P. K. Davis, N. E. Flynn, D. A. Knabe and J. T. Davidson. 1997. Endogenous synthesis of arginine plays an important role in maintaining arginine homeostasis in postweaning growing pigs. J. Nutr. 127(12):2342-2349.

Wu, G. and C. J. Meininger. 2008. Analysis of citrulline, arginine, and methylarginines using high-performance liquid chromatography. Meth. Enzymol. 440:177-189.

$\mathrm{Wu}, \mathrm{G} .1997$. Synthesis of citrulline and arginine from proline in enterocytes of postnatal pigs. Am. J. Physiol. Gastrointest. Liver Physiol. 272:G1382-G1390.

Wu, G. 1998. Intestinal mucosal amino acid catabolism. J. Nutr. 128:1249-1252.

Wu, G., F. W. Bazer, J. B. Hu, G. A. Johnson and T. E. Spencer. 2005. Polyamine synthesis from proline in the developing porcine placenta. Biol. Report 72:842-850.

Yang, Z. H. and X. F. Ming. 2006. Recent advances in understudy endothelial dysfunction in atherosclerosis. Clin. Med. Res. 4(1):53-65.

Yuan, S. B., D. W. Chen, K. Y. Zhang and B. Yu. 2007. Effects of oxidative stress on growth performance, nutrient digestibilities and activities of antioxidative enzymes of weanling pigs. Asian-Aust. J. Anim. Sci. 20(10):1600-1605. 